\title{
Helium-neon laser therapy in the treatment of hydroxyapatite orbital implant exposure: A superior option
}

\author{
QI-HUA XU ${ }^{1,2^{*}}$, CHEN ZHAO $^{3 *}$, JIAN-GANG ZHU ${ }^{2}$, MEI-JUAN CHEN ${ }^{2}$ and QING-HUAI LIU ${ }^{3}$ \\ ${ }^{1}$ Department of Ophthamology, Nanjing Medical University, Nanjing, Jiangsu 210000; ${ }^{2}$ Department of Ophthalmology, \\ The Affiliated Jiangyin Hospital of Southeast University Medical College, Jiangyin, Jiangsu 214400; \\ ${ }^{3}$ Department of Ophthalmology, The First Affiliated Hospital, Nanjing Medical University, \\ Jiangsu People's Hospital, Nanjing, Jiangsu 210029, P.R. China
}

Received November 25, 2014; Accepted June 9, 2015

DOI: $10.3892 /$ etm.2015.2589

\begin{abstract}
The aim of the present study was to evaluate the efficacy of helium-neon laser therapy in the treatment of hydroxyapatite orbital implant exposure and compare the results with those of a combined drugs and surgery regimen. A total of 70 patients with hydroxyapatite orbital implant exposure in 70 eyes were randomly divided into two groups: Helium-neon laser therapy (group A) and drugs plus surgery (group B). Each group contained 35 patients. The healing rates and times of the conjunctival wound were recorded and compared following helium-neon laser treatment or the drugs plus surgery regimen. Changes in the hydroxyapatite orbital implant prior to and following helium-neon laser irradiation were analyzed. A similar animal study was conducted using 24 New Zealand white rabbits, which received orbital implants and were then received drug treatment or helium-neon therapy. In the human experiment, the rates for conjunctival wound healing were $97.14 \%$ in group A and $74.29 \%$ in group B, with a significant difference between the groups $\left(\chi^{2}=5.71, \mathrm{P}<0.05\right)$. Patients with mild exposure were healed after 7.22 \pm 2.11 days of helium-neon laser therapy and $14.33 \pm 3.20$ days of drugs plus surgery. A statistically significant difference was found between the groups $(\mathrm{t}=8.97, \mathrm{P}<0.05)$. Patients with moderate to severe exposure were healed after $18.19 \pm 2.12$ days of
\end{abstract}

Correspondence to: Dr Chen Zhao, Department of Ophthalmology, The First Affiliated Hospital, Nanjing Medical University, Jiangsu People's Hospital, 300 Guangzhou Road, Nanjing, Jiangsu 210029, P.R. China

E-mail: zhaochen201410@163.com

Dr Qi-Hua Xu, Department of Ophthalmology, The Affiliated Jiangyin Hospital of Southeast University Medical College, 163 Shoushan Road, Jiangyin, Jiangsu 214400, P.R. China

E-mail: xu7ganggang@163.com

*Contributed equally

Key words: helium-neon laser, hydroxyapatite, orbital implant exposure helium-neon laser therapy and $31.25 \pm 4.21$ days of drugs plus surgery. The difference between the groups was statistically significant $(\mathrm{t}=7.91, \mathrm{P}<0.05)$. Enhanced magnetic resonance imaging showed that the helium-neon laser therapy significantly promoted vascularization of the hydroxyapatite orbital implant. These results, combined with pathological findings in animals, which showed that a helium-neon laser promoted vascularization and had anti-inflammatory effects, suggest that helium-neon laser irradiation is an effective method for treating hydroxyapatite orbital implant exposure, thereby avoiding secondary surgery.

\section{Introduction}

Orbital deformities that occur following enucleation, evisceration or exenteration are often corrected with hydroxyapatite orbital implantation. Following this surgery, local inflammation or delayed vascularization of the orbital implant may hinder the healing of conjunctival wounds, causing conjunctival dehiscence $(1,2)$ and even orbital implant exposure and prolapse. These complications are usually treated with drugs and secondary surgery (3-5). Orbital implant exposure is currently treated with various surgical techniques, including a dermal fat graft $(6,7)$, acellular dermal graft (8), palate mucosal repair (9), oral mucosal repair (10), Enduragen ${ }^{\circledR}$ graft repair (11), subconjunctival tissue flap repair (12) and fresh amniotic membrane repair (13). These surgical methods are unsatisfactory, however, as they cannot eliminate local inflammation or accelerate vascularization of the orbital implant. Secondary surgery usually causes unsatisfactory restoration, and patients must undergo multiple repair surgeries and sometimes removal of the orbital implant.

It has been well established that laser therapy is useful in several therapeutic scenarios $(14,15)$. A plethora of beneficial effects have been demonstrated for numerous in vitro and in vivo test systems, including antibacterial, antiviral, antitumor, cellular differentiation, immunopotentiating and repair activities (16). In particular, helium-neon lasers based on red light allow primary chromophores to act as endogenous porphyrins (17). Although helium-neon laser therapy has achieved satisfactory results with regard to wound healing $(18,19)$, its application to hydroxyapatite orbital implant exposure has not been reported to date. 
Local helium-neon laser irradiation has been conducted in patients with orbital implant exposure in the First Affiliated Hospital of Nanjing Medical University (Nanjing, China) since 2007; the present study concerns the investigation into the clinical efficacy of the technique.

\section{Materials and methods}

Patients. A total of 70 patients (46 men and 24 women) with hydroxyapatite orbital implant exposure were included in this study between January 1997 and July 2014, nonconsecutively. The mean age of the subjects was 37.6 years (range, 23-62 years). Among the patients, 35 were treated with helium-neon laser therapy (group A): 22 men and 13 women, with a mean age of 36.5 years (range, 25-55 years). In total, 30 patients underwent orbital implantation at the first stage and the other 5 patients that were unable to undergo the first stage operation for various reasons were included in the second stage. The patients in group A were followed up for 2-28 months postoperatively. The remaining 35 patients were treated with drugs and surgery (group B): 25 men and 10 women with a mean age of 39.5 years (range, 24-60 years). A total of 22 patients underwent orbital implantation at the first stage and the other 13 patients at the second stage. The group B patients were followed up for 5-40 months postoperatively. The two groups had no statistically significant differences in age or gender $(\mathrm{P}>0.05)$.

Animal experiment. A total of 24 New Zealand white 7-month-old rabbits (equally male and female) weighing $2-3 \mathrm{~kg}$ were obtained from Nanjing Medical University. The rabbits received 10-mm diameter hydroxyapatite orbital implant (IOI Corp.) and were divided into two groups. In one group, the rabbits were treated with $0.5 \%$ levofloxacin ophthalmic solution and 21,000 IU/5 ml bFGF eye drops (4 times per day) following surgery. The other group underwent helium-neon laser irradiation plus the eye drops. After 2 weeks of treatment, the hydroxyapatite orbital implants harvested from the rabbit eyes underwent pathology examinations.

Degree of orbital implant exposure. Orbital implant exposure of $<7 \mathrm{~mm}$ was considered mild, while that of 7-10 $\mathrm{mm}$ was moderate to severe. Patients were excluded if their orbital implant exposure was $>10 \mathrm{~mm}$, the anterior orbital implant appeared to have prolapsed or there was orbital infection (19).

In this study, 24 patients in group A had mild orbital exposure and 11 patients had moderate to severe exposure. Similarly, in group B, 24 patients had mild orbital exposure and 11 had moderate to severe exposure.

Treatment. The orbital implant (20 mm diameter; IOI Corp., San Diego, CA, USA) was wrapped with a pedicled scleral flap. Implantation was performed following evisceration. In group $\mathrm{A}$, a helium-neon laser multifunction therapy machine (LJL40-HA; Shanghai Institute of Laser Technology, Shanghai, China) was used as follows: Maximum output power, $50 \mathrm{MW}$; emission wavelength, $632.8 \mathrm{~nm}$; main voltage, $220 \pm 22 \mathrm{~V}$; frequency, $50 \pm 1 \mathrm{~Hz}$. The aperture size was adjusted based on the conjunctival sac. Irradiation was applied for 15 min continuously once a day for 10 days. During the follow-up period, patients were administered $0.5 \%$ levofloxacin ophthalmic solution [Santen Pharmaceutical (China) Co. Ltd., Suzhou, China] and recombinant bovine basic fibroblast growth factor (bFGF) eye drops (21,000 IU/5 ml; Zhuhai Essex Bio-Pharmaceutical Co., Ltd., Shenzhen, China) 4 times per day. The patients were rechecked every 5 days postoperatively until the conjunctival wounds had healed. In group B, patients with mild orbital implant exposure were treated with levofloxacin ophthalmic solution and recombinant bovine bFGF eye drops. Patients with moderate to severe exposure underwent surgical restoration and drug therapy if drugs alone did not diminish the exposure. Surgical restoration included conjunctival flap transposition for a conjunctival wound and allogeneic scleral repair for evident implant exposure and scleral dissolution.

Statistical analysis. Data were statistically processed using SPSS software (version 13.0; SPSS, Inc., Chicago, IL, USA). The healing rates were compared using the $\chi^{2}$ test. Healing times were compared using a two independent samples $t$-test. Data expressed as the mean \pm standard deviation. $\mathrm{P}<0.05$ was considered to indicate a statistically significant difference.

\section{Results}

Healing rates. In group A, all 24 patients with mild orbital implant exposure underwent a course of helium-neon laser irradiation, following which their conjunctival wounds had healed, giving a $100 \%$ healing rate. The average healing time was $7.22 \pm 2.11$ days. Conjunctival hyperemia was clearly attenuated, secretion was reduced and eyelid activities were normal. The remaining 11 patients with moderate to severe exposure underwent one course of helium-neon laser irradiation. Four patients achieved conjunctival wound healing, and six more were completely healed following two courses of laser therapy. There was no exudation or conjunctival hyperemia and the eyelid moved freely. One patient with severe conjunctival dehiscence and anterior implant exposure underwent allogeneic scleral restoration and conjunctival flap implantation to repair a conjunctival wound. The conjunctival wound healed following three courses of local helium-neon laser irradiation with no complications.

In group B, 24 patients with mild orbital implant exposure were treated with drugs. Among them, 22 cases healed. The healing rate was $91.67 \%$. The average healing time was $14.33 \pm 3.20$ days, which was significantly longer than that for group A (Table I). The 11 patients with moderate to severe exposure were treated with drugs and surgery. Among them, 4 patients experienced healing. The healing rate was $36.36 \%$, which was clearly lower than that in group A (90.91\%).

The total efficiency rate of helium-neon laser irradiation was $97.14 \%$, which was significantly higher than that for the drugs plus surgery treatment $(74.29 \%)$. A comparison of the treatment outcomes between the two groups is shown in Table I.

Conjunctival healing times. The results showed that the average healing time of conjunctival wounds was 7.22 2 2.11 days for the mild-exposure patients in group A and 14.33 \pm 3.20 days for the mild-exposure patients in group B. The difference was significant $\left(\mathrm{t}=8.97>\mathrm{t}_{0.05(44)}=2.12, \mathrm{P}<0.05\right)$. Patients with moderate to 
Table I. Comparison of conjunctival wound healing rates between the two groups.

\begin{tabular}{|c|c|c|c|c|c|c|c|c|}
\hline \multirow[b]{2}{*}{$\begin{array}{l}\text { Degree of } \\
\text { conjunctival } \\
\text { dehiscence }\end{array}$} & \multicolumn{4}{|c|}{ Helium-neon laser irradiation group (group A) } & \multicolumn{4}{|c|}{ Drugs and surgical treatment group (group B) } \\
\hline & $\mathrm{N}$ & $\begin{array}{c}\text { No. of } \\
\text { healing } \\
\text { cases }\end{array}$ & $\begin{array}{c}\text { No. of } \\
\text { nonhealing } \\
\text { cases }\end{array}$ & $\begin{array}{l}\text { Healing } \\
\text { rate, \% }\end{array}$ & $\mathrm{N}$ & $\begin{array}{c}\text { No. of } \\
\text { healing } \\
\text { cases }\end{array}$ & $\begin{array}{c}\text { No. of } \\
\text { nonhealing } \\
\text { cases }\end{array}$ & $\begin{array}{l}\text { Healing } \\
\text { rate, \% }\end{array}$ \\
\hline Mild & 24 & 24 & 0 & 100.00 & 24 & 22 & 2 & 91.67 \\
\hline $\begin{array}{l}\text { Moderate to } \\
\text { severe }\end{array}$ & 11 & 10 & 1 & 90.91 & 11 & 4 & 7 & 36.36 \\
\hline Total & 35 & 34 & 1 & 97.14 & 35 & 26 & 9 & 74.29 \\
\hline
\end{tabular}

Comparison between the two groups: Mild, $\chi^{2}=0.52<\chi_{0.05(1)}^{2}=3.84, \mathrm{P}>0.05$; moderate to severe, $\chi^{2}=4.91>\chi_{0.05(1)}^{2}=3.84, \mathrm{P}<0.05$; overall, $\chi^{2}=5.71>\chi_{0.05(1)}^{2}=3.84, \mathrm{P}<0.05$.

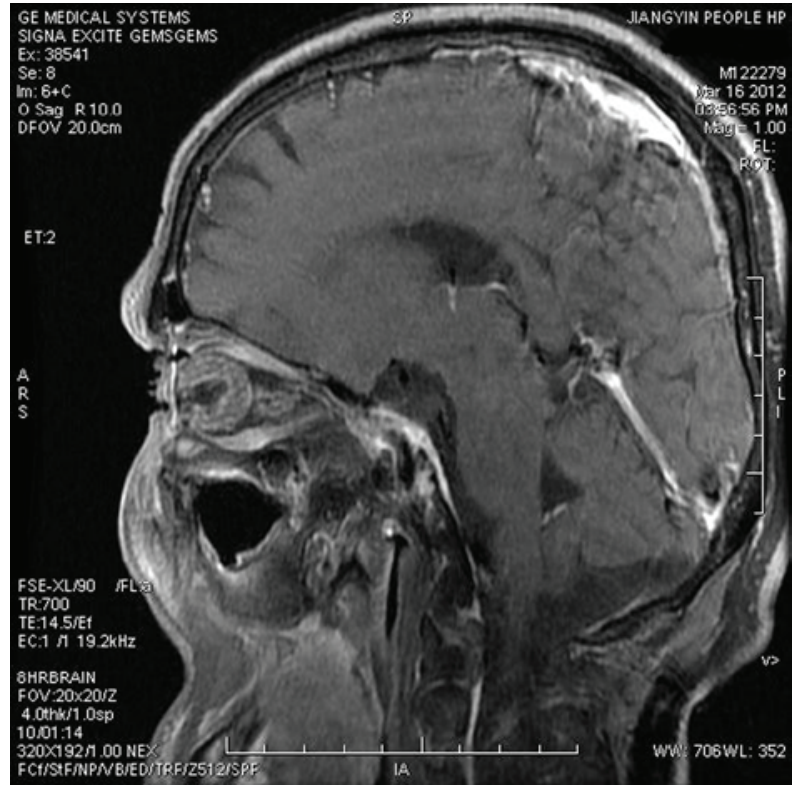

Figure 1. Magnetic resonance image obtained prior to helium-neon laser irradiation.

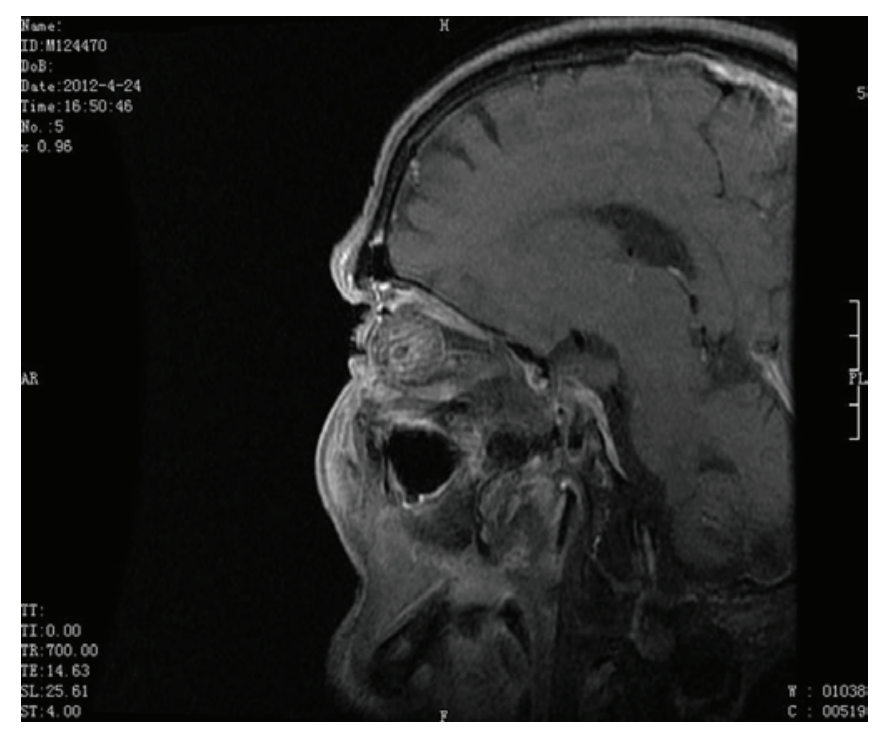

Figure 2. Magnetic resonance image obtained following helium-neon laser irradiation. severe orbital implant exposure had an average healing time of $18.19 \pm 2.12$ days in group A and $31.25 \pm 4.21$ days in group B. The difference was significant $\left(\mathrm{t}=7.91>\mathrm{t}_{0.05(12)}=2.179, \mathrm{P}<0.05\right)$. Helium-neon laser irradiation clearly shortened the healing time of the conjunctival wounds in patients with mild or moderate to severe orbital implant exposure (Table II).

Changes in hydroxyapatite orbital implants prior to and following helium-neon laser irradiation. Patients with moderate to severe orbital implant exposure underwent magnetic resonance imaging (MRI) prior to and following helium-neon laser irradiation. The results showed that the front part of the orbital implant was not vascularized in patients with apparent conjunctival dehiscence (Fig. 1). By contrast, following one course of helium-neon laser irradiation, vascularization of the front part of the orbital implant was clearly visible (Fig. 2). The conjunctival wound was healed with no complications. The findings indicate that helium-neon laser irradiation significantly promotes orbital implant vascularization.

In an animal experiment, New Zealand white rabbits were given 10-mm diameter hydroxyapatite orbital implants (IOI Corp.) and divided into two groups. In one group, the rabbits were treated with $0.5 \%$ levofloxacin ophthalmic solution and 21,000 IU/5 ml bFGF eye drops (4 times per day) following surgery. The other group underwent helium-neon laser irradiation plus the eye drops. After 2 weeks of treatment, the hydroxyapatite orbital implants harvested from the rabbit eyes underwent pathology examinations. In the rabbits that received eye drops alone, there was sparse fibrous tissue around the orbital implant, only a few new blood vessels were evident and a large number of inflammatory cells (mainly neutrophils) and red blood cells were present. Following helium-neon laser irradiation plus eye drops, mature and dense fibrous tissues were noted around the implants. No inflammatory cells were apparent. The findings indicated that, in addition to promoting orbital vascularization, helium-neon laser irradiation has anti-inflammatory effects.

\section{Discussion}

Orbital implant exposure is a common complication following orbital implantation. Custer and Trinkaus (20) estimated that 
Table II. Comparison of the healing times of conjunctival wounds for the two groups.

\begin{tabular}{lcccr}
\hline Exposure & $\begin{array}{c}\text { Healing time in } \\
\text { group A (days) }\end{array}$ & $\begin{array}{c}\text { Healing time in } \\
\text { group B (days) }\end{array}$ & $\mathrm{t}$ & P-value \\
\hline Mild & $7.22 \pm 2.11$ & $14.33 \pm 3.20$ & 8.97 & $<0.05$ \\
Moderate to severe & $18.19 \pm 2.12$ & $31.25 \pm 4.21$ & 7.91 & $<0.05$ \\
\hline
\end{tabular}

Group A, helium-neon laser irradiation group; group B, drugs plus surgery group.

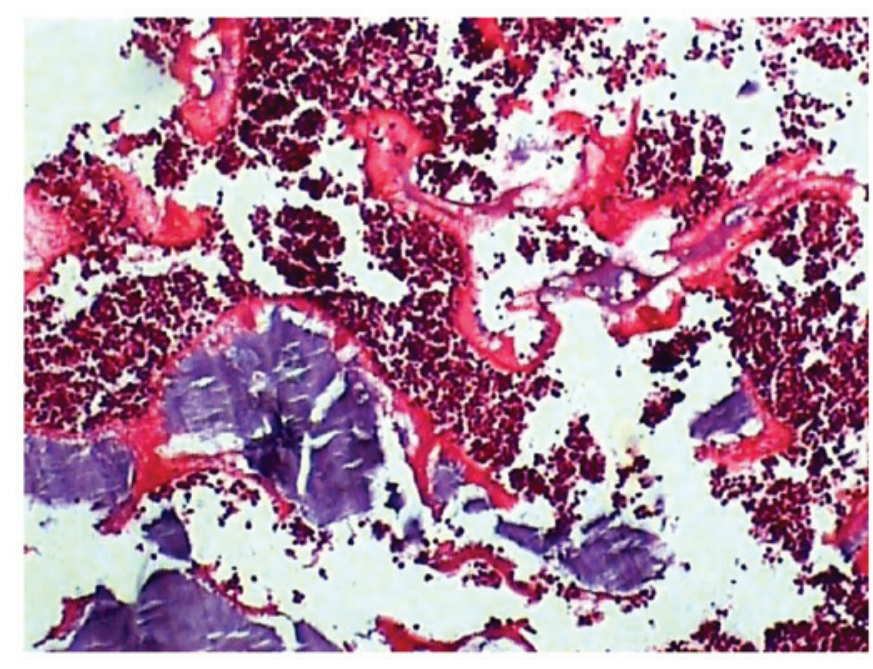

Figure 3. Pathological section of a rabbit orbital implant (stain, hematoxylin and eosin; magnification, x10).

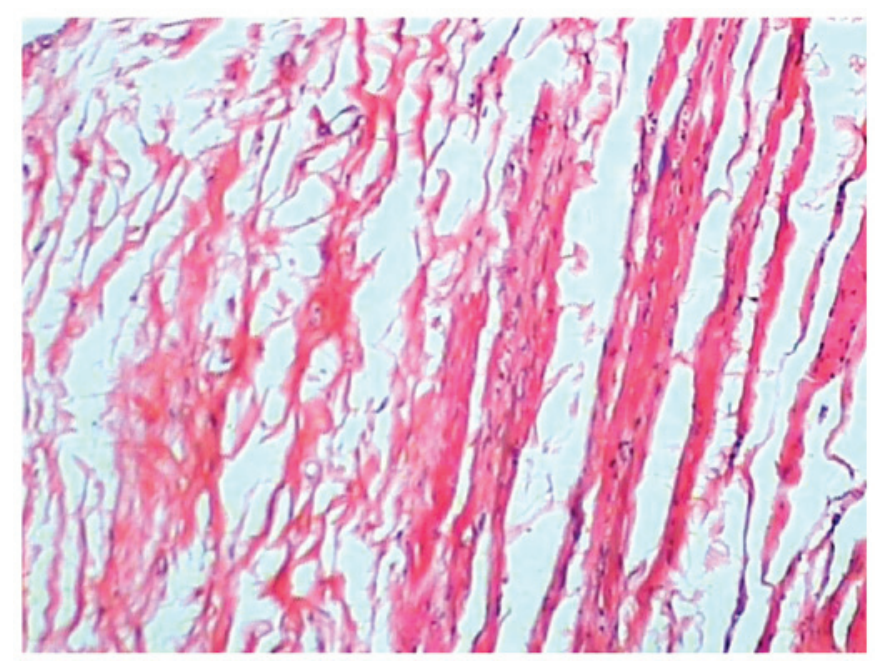

Figure 4. Pathological section of a rabbit orbital implant following helium-neon laser irradiation (stain, hematoxylin and eosin; magnification, $\mathrm{x} 10)$.

the total incidence of postoperative orbital implant exposure in China was $4.9 \%$, and the prevalence in China reportedly ranged from 1.6 to $21.6 \%$ between 1998 and 2004 (21). The majority of patients with mild exposure $(7 \mathrm{~mm})$ and conjunctival dehiscence are healed by drugs, whereas those with moderate to severe exposure undergo both drug and surgical treatment. The surgical treatment may include local debridement, polishing of the orbital implant surface and allogeneic scleral transposition for conjunctival flap restoration $(3-5,20)$. Secondary surgical restoration is sometimes ineffective in patients with severe exposure. Custer and Trinkaus (20) noted that $29 \%$ of severe cases required removal of the orbital implant.

Conjunctival dehiscence and orbital implant exposure following orbital implant surgery are the results of delayed histogenesis of orbital fibrovascular tissue and local inflammatory reactions $(1,2)$. Tambe et al (1) found that all of the patients who failed surgery appeared to have chronic inflammation according to pathological sections of the exposed orbital implant. Sustained local chronic inflammatory reactions may affect orbital implant vascularization, delay orbital fibrous vascularization, reduce the local anti-inflammatory reaction of the orbital implant and hinder local wound healing, ultimately expanding a bulbar conjunctival wound and causing apparent orbital implant exposure. Eye drops mainly function at the conjunctiva so it is difficult for them to reach the orbital implant. Surgical treatment can debride local wounds and restore conjunctival wounds. Since the combination of drugs and surgical treatment cannot prevent orbital inflammation or promote vascularization, their use has a low success rate for treating orbital implant exposure.

Lasers can play an important role in tissue repair. Kazem Sakouri et al (22) postulated that the use of lasers could enhance callus development during the early stage of the healing process in rabbits. Similarly, it has been suggested that low-level laser therapy may accelerate fracture repair or cause increased callus volume and bone mineral density, particularly during the early stages of absorbing hematoma and bone remodeling (23). A previous study has demonstrated that helium-neon laser therapy significantly increased the number of blood vessels after 7 days of irradiation (24).

Helium-neon laser is red light at $632.8 \mathrm{~nm}$. The incident beam can partially reach into $15 \mathrm{~mm}$ of tissue, causing local vascular dilation and accelerated blood flow. The laser thus plays a role in reducing inflammation, has an anti-swelling effect and promotes functional recovery. Calin and Parasca (25) found that a laser at 630-700 nm significantly repaired injured tissue. In addition, low-energy helium-neon lasers strengthen phagocytosis by macrophages and promote the absorption of inflammation (26). Local helium-neon laser therapy contributes to the prevention of the inflammatory reaction and promotes local tissue proliferation and wound healing. These efficacies of helium-neon laser therapy provide strong theoretical evidence for its use in the clinical treatment of orbital implant exposure.

In the present study, 35 patients with orbital implant exposure were treated with helium-neon laser therapy 
(group A), and 34 of them achieved complete healing. The efficacy rate was $97.14 \%$, which was significantly higher than that for patients in group B (74.29\%), who were on a drugs plus surgery regimen. In addition, helium-neon laser therapy markedly shortened the healing time of the conjunctival wounds in patients with mild conjunctival dehiscence and orbital implant exposure (Table II). Enhanced MRI scans and animal experiments (Figs. 3 and 4) confirmed the contribution of helium-neon lasers to the promotion of vascularization and prevention of inflammation. These results have revealed the underlying mechanisms of helium-neon laser therapy for treating hydroxyapatite orbital implant exposure: The technique promotes vascularization of the orbital implant; improves internal microcirculation of the orbital implant; enhances the anti-infection capacity; enhances local vasodilation, accelerating blood flow; and strengthens phagocytosis by macrophages, promoting the absorption of inflammatory cells and thereby promoting the healing of conjunctival wounds.

In conclusion, helium-neon laser therapy is superior to combined drugs and surgery for treating hydroxyapatite orbital implant exposure accompanying postoperative conjunctival dehiscence. It can significantly increase the healing rate of conjunctival wounds and shorten the healing time. This low-cost method is safe and efficient and can serve as a routine precautionary measure for patients in poor local and systemic conditions. In summary, helium-neon laser therapy is an ideal treatment for hydroxyapatite orbital implant exposure.

\section{References}

1. Tambe K, Pushpoth S, Mudhar HS and Sandramouli S: A histopathologic study of orbital implant vascularization. Orbit 28: 50-57, 2009.

2. Buettner $\mathrm{H}$ and Bartley GB: Tissue breakdown and exposure associated with orbital hydroxyapatite implants. Am J Ophthalmol 113: 669-673, 1992.

3. Kuzmanović Elabjer B, Petrinović-Doresić J, Busić M and Henc-Petrinović L: Our approach in the treatment of exposed hydroxyapatite orbital implant. Acta Med Croatica 60: 141-144, 2006 (In Croatian).

4. Lu L, Shi W, Luo M, Sun Y and Fan X: Repair of exposed hydroxyapatite orbital implants by subconjunctival tissue flaps. J Craniofac Surg 22: 1452-1456, 2011.

5. el-Shahed FS, Sherif MM and Ali AT: Management of tissue breakdown and exposure associated with orbital hydroxyapatite implants. Ophthal Plast Reconstr Surg 11: 91-94, 1995.

6. Kim HK and La TY: Treatment of intractable orbital implant exposure with a large conjunctival defect by secondary insertion of the implant after preceding dermis fat graft. Int J Ophthalmol 6: 193-197, 2013

7. Lee BJ, Lewis CD and Perry JD: Exposed porous orbital implants treated with simultaneous secondary implant and dermis fat graft. Ophthal Plast Reconstr Surg 26: 273-276, 2010.
8. Jung SK, Paik JS, Sonn UH and Yang SW: Surgical outcomes of acellular human dermal grafts for large conjunctiva defects in orbital implant insertion. Graefes Arch Clin Exp Ophthalmol 251: 1849-1854, 2013

9. Kaynak P, Karabulut GO, Ozturker C, Perente I, Gökyiǧit B, Demirok A and Yilmaz OF: Remove, rotate and reimplant: A novel technique for the management of exposed porous anophthalmic implants in eviscerated patients. Eye (Lond) 28: 546-552, 2014.

10. Yoon KC, Yang Y, Jeong IY and Kook MS: Buccal mucosal graft for hydroxyapatite orbital implant exposure. Jpn J Ophthalmol 55: 318-320, 2011.

11. Wu AY, Vagefi MR, Georgescu D, Burroughs JR and Anderson RL: Enduragen patch grafts for exposed orbital implants. Orbit 30: 92-95, 2011.

12. Lu L, Shi W, Luo M, Sun Y and Fan X: Repair of exposed hydroxyapatite orbital implants by subconjunctival tissue flaps. J Craniofac Surg 22: 1452-1456, 2011.

13. Xie RL: Fresh amnion transplantation for ocular prosthesis exposure. Zhonghua Yan Wai Shang Zhi Ye Bing Za Zhi 33: 305-307, 2011 (In Chinese).

14. da Guarda MG, Paraguassú GM, Cerqueira NS, Cury PR, Farias JG and Ramalho LM: Laser GaAlAs $(\lambda 860 \mathrm{~nm})$ photobiomodulation for the treatment of bisphosphonate-induced osteonecrosis of the jaw. Photomed Laser Surg 30: 293-297, 2012.

15. Sato K, Moy OJ, Peimer CA, Nakamura T, Howard C, Ko SH, Lee TC and Nishiwaki Y: An experimental study on costal osteochondral graft. Osteoarthr Cartilage 20: 172-183, 2012.

16. Lan CC, Wu CS, Chiou MH, Hsieh PC and Yu HS: Low-energy helium-neon laser induces locomotion of the immature melanoblasts and promotes melanogenesis of the more differentiated melanoblasts: Recapitulation of vitiligo repigmentation in vitro. J Invest Dermatol 126: 2119-2126, 2006.

17. Klebanov GI, Teselkin YO, Babenkova IV, Bashkueva TY, Chiehuk TV and Vladimirov YA: Low power laser irradiation induces leukocyte priming. Gen Physiol Biophys 17: 365-376, 1998.

18. Peccin MS, Renno AC, de Oliveira F, Giusti PR and Ribeiro DA: Helium-neon laser improves skin repair in rabbits. J Cosmet Laser Ther 14: 286-289, 2012.

19. Peccin MS, de Oliveira F, Muniz Renno AC, Pacheco de Jesus GP, Pozzi R, Gomes de Moura CF, Giusti PR and Ribeiro DA: Helium-neon laser improves bone repair in rabbits: Comparison at two anatomic sites. Lasers Med Sci 28: 1125-1130, 2013.

20. Custer PL and Trinkaus KM: Porous implant exposure: Incidence, management and morbidity. Ophthal Plast Reconstr Surg 23: 1-7, 2007.

21. Rong L, Fang Q and Ren DY: Hydroxyapatite ocular prosthesis implantation under double cap sclera after the modified enucleation. Yan Ke Xin Jin Zhan 26: 59, 2006 (In Chinese).

22. Kazem Shakouri S, Soleimanpour J, Salekzamani Y and Oskuie MR: Effect of low-level laser therapy on the fracture healing process. Lasers Med Sci 25: 73-77, 2010.

23. Liu X, Lyon R, Meier HT, Thometz J and Haworth ST: Effect of lower-level laser therapy on rabbit tibial fracture. Photomed Laser Surg 25: 487-494, 2007.

24. Garavello I, Baranauskas V and da Cruz-Höfling MA: The effects of low laser irradiation on angiogenesis in injured rat tibiae. Histol Histopathol 19: 43-48, 2004.

25. Calin MA and Parasca SV: In vivo study of age-related changes in the optical properties of the skin. Lasers Med Sci 25: 269-274, 2010.

26. Li GZ: Physical therapy for skin diseases. In: Clinical Dermatology in China. Zhao B (ed.). 3rd edition. Jiangsu Science and Technology Press, Nanjing, pp231-301, 2001. 